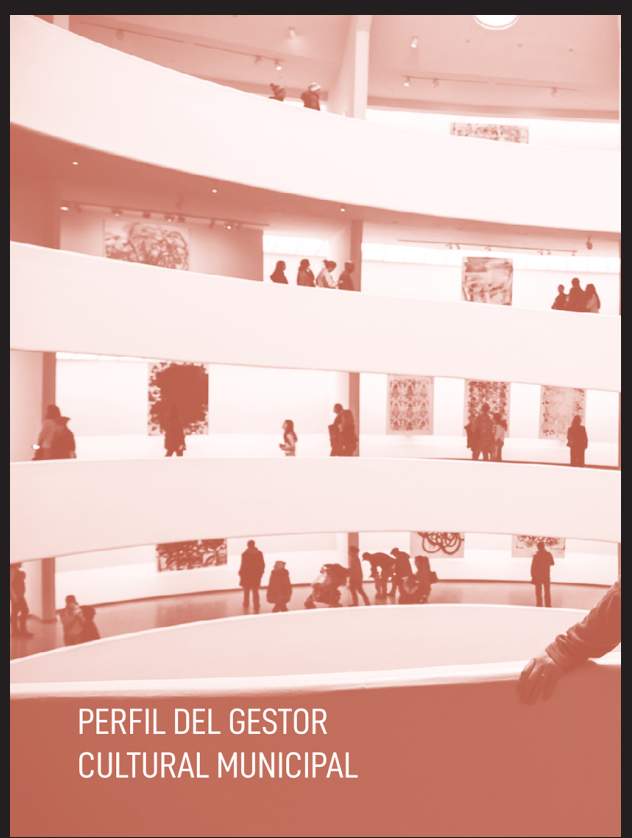

urante este año 2019, en el marco del Observatorio Cultural del Proyecto Atalaya, se ha llevado a cabo el desarrollo de una investigación por encargo de la Universidad de Cádiz y la Universidad Internacional de Andalucía acerca de una de las cuestiones más discutidas, comentadas y analizadas hoy en día por los y las profesionales de la gestión cultural: identificar las competencias que requiere el perfil del profesional de este ámbito, así como lograr la dignificación de la profesión tan poco reconocida por otras áreas.

Para ello se llevó a cabo una investigación a desarrollar en cuatro fases, y comprendida entre los meses de enero a julio, en las que han intervenido gestores y gestoras culturales de diversa índole y ámbito profesional, además de contar con expertos y expertas en la materia.

En la primera fase, se realizó un mapeo y revisión de los planes de estudios de los grados y posgrados en gestión cultural que están en la actualidad vigentes en nuestro país. Una de las principales conclusiones que ponen de manifiesto es el perfil tan tradicional e inadecuado que ofrecen dichas entidades en sus planes de estudio, insuficientes hoy en día para manejar y adaptarse a las especificidades de los múl-

\section{Perfil del gestor cultural municipal}

Dra. Cristina Ortega Nuere

Dr. Antonio Javier González Rueda

Dra. Isabel Verdet Peris

Investigación comisionada por: Universidad de Cádiz (UCA) y Universidad Internacional de Andalucía, en el marco del Observatorio Cultural del Proyecto Atalaya. Septiembre 2019, Cádiz

68 páginas

tiples ámbitos culturales en los que el gestor desarrollará su labor profesional a lo largo de su trayectoria, y en particular a las del ámbito municipal.

Este punto va en contraposición con la realidad que han planteado los gestores o gestoras municipales, así como los expertos y expertas que han intervenido en las fases posteriores de dicha investigación.

De forma paralela y durante los meses de mayo y junio, se llevaron a cabo, por una parte, una serie de entrevistas a especialistas de la gestión cultural del ámbito nacional tales como Lluís Bonet, Luis Ben, Gemma Carbó, Teresa Muela y $\mathrm{M}^{\mathrm{a}}$ José Quero, así como una encuesta a nivel nacional que se distribuyó entre profesionales de la gestión cultural en el ámbito municipal, gracias a la colaboración de asociaciones estatales y autonómicas.

En una fase posterior y última, realizada en el mes de julio, tuvo lugar la celebración de un grupo focal de profesionales en gestión cultural municipal. Fue una toma de contacto real, con esos gestores y gestoras cuyo trabajo refleja el día a día de la gestión cultural en nuestro territorio, vista desde diferentes puntos de vista del ámbito local y de proximidad.

Como se apuntaba anteriormente, la realidad presentada tras la revisión de los planes de estudios de los trece grados y posgrados consultados en el mapeo difiere mucho de 
la realidad demandada por los expertos y expertas, gestores y gestoras municipales y que son tan necesarias para el desarrollo de su trabajo diario: Lo territorial está completamente ausente de los programas formativos, a pesar de que es vital en opinión de las personas consultadas, así como desde el punto de vista de los expertos y expertas entrevistados.

Podríamos decir que muy pocas de las entidades académicas incluyen en sus planes de estudios y más concretamente en sus materias, alguna referencia a las competencias específicas en materia de cultural territorial que debería de adquirir el gestor y gestora cultural para obtener conocimientos del territorio, del espacio y de la gestión de recursos para el desarrollo local y municipal.

De entre ellos hacemos referencia a la Universidad de Córdoba, la Universidad de Valladolid, los cuales fijan esta materia en su territorio, haciéndolo demasiado específico su focalización. Sin embargo, la Universidad Rey Juan Carlos atiende ese conocimiento de lo territorial «apuntando la necesidad de manejar diferentes niveles de complejidad territorialidad, siendo capaz de adaptarse el conocimiento adquirido por el gestor/a a las realidades cambiantes que éste puede tener a lo largo de su trayectoria profesional».

Las áreas más tradicionales, tales como el conocimiento socio- histórico, la cooperación internacional, la dimensión económica y la investigación, ocupan un lugar muy destacado y principal en todos los planes de estudios en pos de otros factores sociales tan importantes y a tener en cuenta en los tiempos que corren. Cabe destacar la ausencia de materias tan de primer nivel como la cuestión de género y la comunicación digital en los programas de formación. Sería fundamental su incorporación a estos planes, aunque sea de manera transversal, para un más correcto desarrollo de la labor del gestor/a cultural en el ámbito local.

Centrándonos en la labor que desarrolla diariamente el gestor/a cultural municipal, debe actuar como mediador/a en su territorio, manteniendo el vínculo de unión entre los diferentes agentes que operan en él para establecer y conseguir buenas relaciones tanto a nivel de participación como de creación. Eso no exime al gestor/a cultural de co- nocimientos territoriales en cuestiones más jurídicas, administrativas y organizativas de su entorno. Según palabras de Luis Ben, recogidas en su entrevista, el profesional de la gestión cultural

tiene que saber qué es un ayuntamiento, desde el despacho del alcalde o alcaldesa, hasta dónde están los servicios sociales, culturales y de todo tipo. Básicamente yo lo resumiría en la palabra territorio, todo lo que comporta el territorio para la gestión cultural.

Muchas veces la indefinición de las funciones y tareas de la figura del gestor o gestora cultural municipal, hacen de ellos el «chico o chica para todo» según apuntan todos los expertos/as consultados en este proceso. Ello hace que esa ausencia de regulación genere una indefensión profesional que año tras años se ha visto acrecentada, mermando al profesional de la gestión cultural.

El apego a su territorio y la vocación muchas veces son las únicas armas con las que estos profesionales cuentan. En muchos casos, aunque cada vez sean menos, se ha detectado la falta de formación en determinados campos, ya que se han detectado vacíos o gaps entre la oferta desde el ámbito académico y la necesidad reclamada por los profesionales de la gestión cultural local.

Este estudio nos apunta que lo territorial debe estar presente en los planes de estudios vigentes en nuestra sociedad. No es una moda, como puede ocurrir con otras materias, sino que han de presentarse como una herramienta que abarque diferentes cuestiones y que haga que los gestores/as culturales municipales puedan adaptarlas a las especificidades de sus territorios para poder desarrollar su actividad local.
Verónica Rivas Serrano

Técnica de gestión cultural 